ganglion anaesthesia has persisted though pressure could be felt, yet the relief from pain appears to be equally good.

In many cases, though total ganglion anaesthesia is produced at the time of injection, yet the anaesthesia of the first and second divisions wears off, perhaps completely, in from ten minutes to an hour, though the third division remains totally anaesthetic. This is no doubt due to the ganglion cells having been shocked, and not destroyed, by a partial infiltration only. In such a case pain is liable to recur after twelve months or two years, as in a case of ordinary injection of the nerve. With total destruction of the ganglion there is the same liability to keratitis as with the operation of gasserectomy, but if the lids are kept carefully closed by strapping for the first week and the conjunctival sac washed out with boracic lotion twice a day, I have found little or no trouble with my later cases. The lids, however, should be kept closed from the beginning, and it is unwise to wait and see whether keratitis develops, as then it will be necessary to keep them closed for a much longer time.

Hutchinson's partial gasserectomy avoids the danger of keratitis, but is not a certain permanent cure, as I have seen three such cases relapse with neuralgia.

\section{Bilateral Neuralgia.}

Bilateral trigeminal neuralgia is comparatively rare, though I have seen and injected 25 bilateral cases, usually at different dates, but on several occasions I have injected both sides, one after the other.

Gasserectomy is an impossible operation for bilateral cases. of trigeminal neuralgia, owing to the necessary destruction of the motor branch of the fifth nerve on each side and consequent jaw-drop. Alcohol injection has the advantage that the nerve injury is less complete, and the motor nerve fibres regenerate. In one case I produced jaw-drop for two and a half months, which recovered completely later. On December 10th, 1919, I injected the left Gasserian ganglion in a woman of 49 , for neuralgia of the left upper jaw, whose right Gasserian ganglion I liad previously destroyed by alcohol injection seven years previously. She was still totally anaesthetic over the whole right fifth distribution, just as much as in any case of gasserectomy, though in her case the motor branch had recovered well, and she had quite good right temporal, masseter, and pterygoid muscles. Injection of the left Gasserian has now produced in her case total anaesthesia of the whole of the face and front half of her head, though she can chew fairly well by means of the muscles on the right side, and those on the left side will doubtless recover also later. So far as I know, bilateral destruction of the Gasserian ganglia has never previously been done.

Method of Injecting Alcohol.

As regards the methods of practising alcohol injection, details have already been published and need not here be repeated, though I would like to insist on the advisability of using the method of trial and test. That is to say, when the needle is thought to have struck the nerve injest a few drops of 2 per cent. novocain, and, after waiting half a minute, test the skin distribution of the nerve for anaesthesia. If none has developed do not inject alcohol, but try again to find the nerve. As soon as anaesthesia appears to novocain injection, then complete by injecting about $1 \mathrm{c.cm}$. of 90 per cent. alcolol when total anaesthesia to touch, pin, and pressure will develop almost instantaneously if the nerve at the foramen ovale or foramen rotundum has been correctly hit.

\section{Results.}

In almost every case, as soon as anaesthesia develops from the injection, the neuralgic spasms cease, and they can no longer be started by any chewing movements or rubbing the face.

The duration of the cure rarely lasts less than twelve montlss, if good anaesthesia has been obtained, and in the majority the relief from pain lasts from two to three years. Very many of my cases have been quite free for four or five years, one six and a half years, another seven years, another nine years after nerve injection only, while I expect my cases of ganglion injection to be permanen cures, just as if gasserectomy had been done. No trophic effects on the skin are ever seen. Keratitis is a risk if the cornea is anaesthetic after injection of the ganglion, but this may always be avoided by proper precautions.

\section{THE SIGNIFICANCE OF ACIDOSIS IN} CERTAIN NERVOUS DISORDERS.*

$$
\text { BY }
$$

B. H. SHAW, M.D.,

MEDICAL SUPERINTENDENT, COUNTY MENTAL HOSPITAL, STAFFORD.

Acrdosis, as evidenced by the presence of acetone bodies in urine, is frequent in cases of acute delirium, confusional and stuporose states, certain melancholic conditions, and in epilepsy.

The following notes are taken from two recent deaths resulting from extreme acidosis:

1. E. J., a mischievous, weak-minded boy of impulsive tendencies, aged 15, admitted in September, 1917. He was well nourished, and took his food very well indeed. He had had no fits previously. During the night of December 30th, 1919, he had a severe typical epileptic fit, and lapsed into a condition of cerebral irritation, with paresis of his legs and conjunctival injection. Specific gravity of urine 1024 ; no albumin or sugar, injection. Specific gravity of urine 1024 ; no albumin or sugar, ment and improved, the acetonuria disappearing, and he conment and improved, the acetonuria disappearing, and he continued to take his food well. On January loth he again de-
veloped strong acetonuria, which did not yield to alkaline treatment, and he died at $9.40 \mathrm{a} . \mathrm{m}$. on the $16 \mathrm{th}$.

Post-mortem Lixamination.-Intense minute injection of the pia arachnoid in a patchy fashion, especially marked over sulci and along veins, one large patch extending over the vertex of the left hemisphere; numerous puncta cruenta on section of the cerebral tissue; strong acetone reaction in cerebro-spingl fluid and blood. Microscopical examination showed minute vascular engorgement, diffuse and central chromatod minute neurone body, and degenerative changes in words, primary degeneration of changes in nuclei-in other glands showed some congestion and fat deficiency; other organs apparently normal.

apparently normal. February 4 th in a state of acute confusiou, had admitted on February 4 th in a state of acute confusiou; had been ill for six weeks prior to admission. He was, on admission, in a state of restless noisy excitement, continually wet and dirty, rendering it impossible to collect his urine for examination. He was put on milk and other extra diet, which he took satisfactorily. He was extremely feeble when admit

Post-mortem Examination.-Cadaver in good condition, marked opacity and thickening of the pia arachnoid, with much recent minute injection and patchy ecchymotic areas. Brain tissue showed numerous puncta cruenta on section. reaction strongly marked in cerebro-spinal tuid. Acetone in excess in pericardial tluid and in the blood, which was examination pericardial fluid and in the blood. Microscopio examinatiou showed engorgement of vessels, with some minute changes, and absence of pigment. Suprarenal glands softened, scanty fat; liver somewhat fatty; other organs normal.

In mental cases it is the exception to find post mortem a normal transparent pia arachnoid, Secondly, in long. standing cases of epilepsy almost the only cliange met with may be a thickening and opacity or milkiness of the pia arachnoid; this thiclsening and opacity I regard now as most probably due to congestive attacks resulting from acid intoxication. These congested areas are most pronounced over the vertex where the membrane is thickest and the underlying nearones mainly motor.

Thirdly, after death in status epilepticus there is intense congestion of the membranes and the cells show the pro. found structural changes of primary degenerationstructural changes which I have shown to be also present in the cases mentioned. It is of interest to note here that the meningcal appearances in these cases are very similar to many I have seen in the Balkans as a result of malignant malaria, and in which the symptoms indicated intense toxaemia, no doubt due to deficient oxidation as a result of the destruction of vast numbers of erythrocytes and also to the haemoglobin and oxyhaemoglobin set free in the plasma behaving as weak acids. Addison, Lusk, and Grallam consider that the rise in heat production in and anaemias is due to the pathological production of lactio acid from carbohydrates in consequence of an inadequate supply of oxygen to the cells. Recently I have had two cases of confusion following malignant malaria contracted at Salonica, one of whom had definite acidosis periodically while here.

*Abstract of paper read at a Staffordshire Branch meeting of the 
Notes on twelve cases were quoted, in which the acidosis was associated mostly with delirium, confusion, mild melancholia, stupoi, epilepsy and masked epilepsy, and it was pointed out that in cases which recover improvement synchronized with diminishing acidosis. Haenolysis of erythrocytes by acetone bodies and bile acids simply means cellular disintegration. Taking into account the other still more destructive ferments present in acidosis, it is obvious that these substances in the blood and body fluids must have a most irritative and disastrous effect on tissue cells. This is already evideuced by the degencratire cell changes noted in the post-mortem examinations alluded to. If the acidosis is intense or continued for a lengtli of time, or if the patient gets frequent recurrences, permanent damage to the neurones nust ensue.

It was next pointed out that the adult human brain contained practically 2 per cent. of cholesterol, while children's brain tissue contained much less-a child 3 months old only 0.69 per cent. This substance can be shown in vitro to exercise a protective function on erythrocytes with regard to the action of haemolytic agents such as autolytic ferments and acids, and it is therefore suggested that the more serious cerebral effects of acidosis in young children may be traceable to this deficiency of cholesterol as compared with adults.

Referring to ferment action, it was mentioned that the diastatic content of urine in cases of acetonuria was somewhat higher than normal, and also it was pointed out that pancreatic lipase which is normally present in blood became haemolytic when activated by fat. In reference to this, serums from different types of mental disorder were inrestigated as regards the effect on them of tryptic digestion. The serums were drawn at the same time of day in every case, primarily for syphilitic serodiagnosis, and in the results the serum in cases of chronic alcoholism, chronic melancholia, and epilepsy, showed a higher acid content as compared with others. Charon and Briche's observation that fits are most frequent at night time, when the reaction of the blood tends most towards acidity, was confirmed. The relationship betwcen tuberculosis and epilepsy and the influence of acidosis in favouring microbic infection was pointecl out. It was suggested that Biedl's glycosuria resulting from throwing the thoracic duct out of circulation was due to the absence of a ferment derived from lymphocytes, and that the lymphocytosis present in such diseases as tuberculosis, typhoid fever, malaria, and epilepsy, is an evidence of increased ferment action and acidosis. It was pointed out that the adrenals, as well as being concerned with sugar elaboration, have anticlotal properties as regards autolytic agents ; in sympathetic disturbances serious interference with cell metabolism and consequent acidosis may result. Thus :

Fright or anxiety produces hyperglycaemia; this is probably due to stimuli emanating from the brain passing over the splanchnic nerves, in part to the liver, inducing acetone formation and the splitting up of glycogen, and also to the supration and the splitting up of glycogen, and also to the suprarenals, causing a discharge of adrenalin. Constant action of resulting loss to the organism of the protection normally resulting loss to the organism of the protection normally afforded against agents producing cell autolysis. Further, quently the presence of acetone in the body fluids directly inhibits the action of adrenalin. . . . Der enerative suprarenal changes are very coustantly met with at necropsies on the insane. In epilepsy, Prior states that out of twenty suprarenal glands examined by lim degenerative changes were present in fifteen; also, in adlition to adrenalin being readily precipitated by acetone in solution, its normal destruction in the blood is inhibited by any tendency towards acidosis.

The production of acid from glucose by the streptococci responsible for pyorrhoea alveolaris was referred to, and the frequency of this affection in cases of mental confusion instanced.

After reference to previous experimental work on animals, the following evidence of the toxic effects of acetone-containing urine was mentioned:

Two rabbits were taken, both bucks from the same litter and each weighing $3 \mathrm{lb}$. Into the first rabbit $2 \mathrm{c.cm}$. of urine from a patient suffering from marked acetonuria was injected intravenously, with the following result:

In a few minutes he became drowsy and lethargic, taking no notice of food though previously feeding with avidity. Incoordination of hind legs set in and paresis; breathing, at firs rapid, became appreciably slower. In half an hour he looked very ill, hunched up, fur ruffled, movement of nostrils spas-
modic and slow; remained in one place; resistive to stimuli ; shut eyes occasionally; half an hour later hind leg paresis had
passed off, although still lethargic and disinclined to move.

Into the second rabbit the same amount of the same urine, but one-third saturated with anhydrous sodium carbonate, was injected intravenously. This injection has no apparent effect on the animal. It had previously been ascertained that $2 \mathrm{c.cm}$. of normal urine had no effect on a rabbit when injected intravenously.

\section{Treatment.}

In mild cases the indications are rest, warm clothingin view of the fact that acidosis is nearly always associated with low blocd pressure; sleep, nutritious diet-avoiding fat and including plenty of carbolydrates, bynogen, Allenbury's diet and such artificial foods; free purgation and alkaline medication. Potassium citrate is very useful, as in addition to the fact that it chauges into carbonate in the blood it provides citric acid, which has the effect of restoring fat metabolism to normal, thereby reducing directly the acetonaemia. This, combined with the carbonates of calcium and lithium and the bicarbonate of soda, malies a very useful prescription. The more bases given the better. Free ventilation is necessary to secure an adequate supply of oxygen.

In a case showing more serious symptoms, complete rest in bed and, in addition to the above, enemata of $20 \mathrm{per}$ cent. glucose solutions; while in a severe attack it may be necessary to give glucose or sodium bicarbonate intra. venously. It might indeed be advantageous to consider gum saline intravenousiy, as Bayliss suggested in wound shock. Glucose, it - must be recollected, may behave as a weak acid in the blood.

Unless absolutely necessary for the provision of sleep as little drugging as possible and as little disturbance in the way of chatter and interference-the exhausted and damaged neurone has quite enough to put up with. Bo firm and make the patient realize that his is a serious bodily disorder. In all but the mildest cases send the patient to hospital as soon as possible. The acetonuria having disappeared, continue a full dose of the alkali towards evening and give a mixture of iron and arsenic. The experiments of Crile show that in these conditions strychnine is contraindicated, as it caused cell changes precisely similar to those resulting from the emotions, toxins, and foreign bodies-namely, hyperchromatism succeeded by chromatolysis. With regard to means of control of the kinetic drive, Crile also states:

Whatever the activation, whether infection, emotion, injury or Graves's disease, morphine measurably controls the outwari phenomena such as pulse rate, respiratory exchange, sweating thirst, restlessness, acid exc:etion, fever, muscular action, aurd pain. . .

And it is interesting to note that so far back as 1822 De Quincey, in his Confessions, states opium to be

-. under an argument undeniably piausible alleged. by myself, the sole known agent, not for curing when forme English scourge of philst likely to ke formed, the great

He considers that he himself was cured of phthisis between the ages of 22 and 24 by the regular and continued use of opium. There is at present here a patient, at one time a confirmed epileptic, who was given, many year's ago, continuous and gradually increasing doses of opium for a number of years. During this period the fits disappeared, nor have they ever returned, though for a good many years now the opium habit has doeen broken off.

In conclusion, attention was drawn to :

1. The profound structural alteration in the neurone caused by acidosis, and the extreme danger of perma. nent injury to it by continuance of the condition or by frequent attaclis.

2. The urgent need of early diagnosis, and the recognition that such cases are very ill indeed, and need complete rest and proper treatment, or they may become invalids for life and a burden on the coinmunity.

3. The simplicity of the diagnosis.

4. The fact that, as a rule, acidosis can be readily counteracted by efficient treatment. 
5. The need-in view of acidosis being a probable etiological factor in epileptic states - for careful in vestigation, and the probability that, if such is the case, efficient allaline treatment may cure the condition if recognized at the onset of the tits. The giving of wromides would seem to be dangerous in such a state, us it only tends to dull cellular activities; later on it may be of use in treating nerve cells which have acquired vicious habits.

6. The danger to the patient in not adopting a firm attitude. If such cases are at once sent to hospital before serious mental symptoms come on there would soon be marked diminution in the admission rate at asylums.

7. The predisposition to microbic diseases afforded by acidosis, above all to tuberculosis. 'As regards children, there are questious which can best be answered by the general practitioner; for instance :

What is the relationship betwcen "biliousuess" in children and subsequent. tuberculosis? Are the sexes equally subject to acidosis? Does it throw any light on the greater mortality of nuale children?

With regard to tuberculosis:

Is it a question of the optimum reaction of the medium necessary for the growth of the tubercle bacillus? In other words, do certain individuals, as a result of errors of nutrition or faulty cell metabolism, offer a more favourable pulmonary or lympliatic culture medium for the growth of the tubercle bacillus than do other's?

Finally, is this whole question of acidosis, within limits, at the bottom of what we understand by lieredity in respect to disease processes? Is it an effort on the part of the organism to autolyze itself? All tliese questions are of extraordinary interest, and the whole subject may bring us vastly nearer a proper compreliension of certain processes which up to the present have been shrouded in mystery.

\section{THE CARE OF CRIPPLED CHILDREN.}

G. R. GIRDLESTONE, M.B., F.R.C.S.

VISITING SURGEON, HEADINGTON ORTHOPAEDIC HOSPITAL; HONORARY DORGEON, SHROPSHIRE SURGICAL HOME; HONORARY ASSISTAN
ORTHOPAEDIC SURGEON, RADCLIFFE INFIRMARY, OXFORD.

Crippled children need both treatment and education; only thus can they be restored to active citizenship, healthy-minded and, so far as may be, healthy-bodied.

In a former paper, published in the BRITISH MEDICAI Journal, October 11th, 1919, attention was called to the crying need for effective treatment for crippled children, and a system of orthopaedic hospital-schools and outpatient clinics designed to carry out the work was out lined. It was estimated that about 10,000 beds would be required for the whole of England and Wales, but it was pointed out that new construction was not involved to this extent, both because in some places hospitals carrying out this work already existed, and in other places there were hospitals in use by the War Office or Ministry of Pensions which would be suitable, and could eventually be made available for this civil orthopaedic work.

Those who have studied the problem feel very strongly that provision for the treatment and all-round education of crippled childron is the reverse of an extravagance, even in the present financial straits. The following figures are taken from the report on "An inquiry concerning physically dofective adults and children " carried out by the City of Birmingham Education Committee in 1911. Their capacity for work was a subject specially noted, and it was found that among 1,001 cripples over the age of 16 only 111 were "able to do remunerative work at home," and 531 were " unable to do any remunerative work." Now it is the experience of those who work at hospitals for cripples that 90 per cent. can be cured or improved sufficiently to enable them to take a share in industry if the disability is tackleâ early and efficiently and training given.

It is true that there must be expenditure, perhaps for six months, during the active treatment of a crippled child. and that in some cases his education expenses afterwar $\mathbf{s}$ may be high, But from the financial point of view alone it is a clear economy, for he is thus enabled to become a pro- ducer instead of a dependant for the many years that follow. Further, these crippled children are already being maintained somewhere and by somebody. Many are in workhouses, infirnaries, or industrial lıomes, and quite out of touch with expert treatment. A large number have to be admitted to general hospitals on account of the scverity of their condition; this is especially true of cases of tuberculosis of the spine, hip, and knee-the very cases that need many months or seccral years of unremitting treatment in open-air wards in the country with plenty of good food. These are the children above all others for whom the hospital-school and continued supervision are needed. On all these children money is now being spent, but with very imperfect results. On the other hand, a certain number of orthopaedic hospitals, orthopaedic departments of general hospitals, and hospital-schools for crippled children are already doing most excellent work; they can only deal with a minority of the cases, yet their very existence means that so much of the capital cost lias already been faced, and so much of the maintenance expense is already being found.

In some places new hospital-schools for crippled children are needed, but almost ererywhere thero is waste and inefficiency due to lack of the combination of education and treatment, of the fellow-working of all the forces that have hither'o worked apart, and of continuity of orthopaedic supervision. The recognition of this is neither new nor singular, as the following quotations will show.

1. Report of the City of Birmingham Education Committce March $29 t h, 1912$ :

"More systematic co-operation and definite co-ordination betreen the local education authority and the hospital and medical charities, especially those which deal with orthopaedic cases, (are needed). In England, speaking gencrally, paedic cases, (are needed). In England, speaking gencrally, the divorce betreen these two organizations and their vision is complete. The success which has attented the vision is complete. The success whion of eduction and cure of cripples in America and joint work of education and cure of cripples in America and
on the Continent is in no small degree due to their close on the Continent is in no small degres
co-operation and identity of outlook."

2. Report of Census of Cleveland, Ohio, 1916:

"The need does not arise from failure to recognize separately the medical and educational requirements, but the failure to co-ordinate these and other forces affecting the life of each crippled child."

On the completion of tineir treatment most of the clildren would be able to go to ordinary schools. In towns some "special schools" would be advisable, but certainly far fewer than are called for now, when many children are allowed to remain crippled needlessly. As the cases are sent in progressively earlier the reduction of the number of children too crippled to attend ordinary schools will become greater in the same degree.

For a few children, eitluer very severely crippled or living too far from a school, a "residential school "would be needed in each district, and this should be in the same grounds as the hospital-school. On their discharge from the hospital these children would then remain under the supervision of the orthopaedic surgeon and continue to attend the school and workshops. 'I'he advantages would be many, including administrative, educational, and works. shop economy, and facility of orthopaedic supervision.

The publication of the paper already mentioned brought some of those whose work lay specially in the treatment of crippled children into touclr with others who had done much for their education and training. These mutual interests have combined, and the "Central Committee for the Care of Cripples" has been formed. Its purpose is to represent and help voluntary associations devoted to the welfare of cripp'e , and to push for wa:d the work in every possible way. This committee has become associated with the "Central Council for Infant and Child Welfare," and has an office at 20, Berkeley Street, IV.

Whenever schemes are put forward or new associations formed there is alarm amongst existin $\mathrm{n}$ organizations, for they naturally feel anxious lest their proved work is to be set on one side. In this case probably the feeling has been-"Is some new and theoretical system of State Service to start afresh with the slate wiped c'ean, and then perhaps never to work with the same sympathy and enthusiasm?" That is the last thing desired. Rather is the aim to unite and help the present efforts, to combine the workers and put better tools into their hands, and to make the attainment of results easier and quicker. 